\title{
Estabelecimento in vitro e micropropagação de maracujá silvestre (Passiflora foetida L.)
}

SOARES, W.S. ${ }^{1,2, *}$; RÊGO, M.M. ${ }^{1,3}$; RÊGO, E.R. ${ }^{1,3}$; BARROSO, P.A. ${ }^{1,4}$; NASCIMENTO, K.S. ${ }^{1,2}$; FERREIRA, K.T. ${ }^{1,2}$ ${ }^{1}$ Laboratório de Biotecnologia Vegetal, Centro de Ciências Agrárias, Universidade Federal da Paraíba, CEP: 58397000, Areia-Brasil *wellington23santos@hotmail.com; mailson@cca.ufpb.br; elizanilda@cca.ufpb.br; pa.barroso@hotmail.com; kaline_csr@hotmail.com; karmithhaina@hotmail.com ${ }^{2}$ Graduando em biologia, bolsista iniciação cientifica; ${ }^{3}$ Bolsista de produtividade em pesquisa-CNPq ${ }^{4}$ Mestranda em Agronomia, bolsista CAPES

RESUMO: Entre as espécies do gênero Passiflora, a $P$. foetida $L$. apresenta a maior variabilidade genética e tem grande importância medicinal, pois é usada no tratamento de doenças como asma, icterícia, e na forma de emplastros, para as erisipelas e doenças de pele com inflamação. Portanto, são necessários estudos que visem a micropropagação e conservação. As sementes de $P$. foetida $L$. apresentam dormência e muitas vezes, levam alguns meses para germinar, produzindo mudas desuniformes e de baixo vigor. Neste sentido, a cultura de tecidos apresentase como uma forma alternativa a propagação. Assim, o objetivo do trabalho foi estabelecer e micropropagar $P$. foetida $\mathrm{L}$., para formação de um banco de germoplasma. Para tanto, sementes foram escarificadas, desinfestadas e inoculadas em meio MS(1/2) sem reguladores de crescimento e cultivados por 66 dias. Explantes de hipocótilos obtidos de plantas germinadas in vitro, foram cultivados no mesmo meio suplementado com 1,0 $\mathrm{mg} \mathrm{L}^{-1}$ de BAP. Na fase de estabelecimento, $45 \%$ dos explantes brotaram e formaram gemas axilares. $88,9 \%$ dos explantes de hipocótilo induziram brotação e $11,1 \%$ produziram calos. Plântulas regeneradas com 1,82 cm de altura, com raízes foram aclimatadas.

Palavras-chave: Passiflora, planta medicinal, micropropagação

ABSTRACT: In vitro establishment and micropropagation of Passiflora foetida L. Among the species of the genus Passiflora, P. foetida L. presents highest genetic variability and also great medicinal importance. This species is used in the treatment of diseases such as asthma, jaundice, and in the form of poultices for erysipelas and skin diseases with inflammation. Therefore, studies are needed to preserve them. Its seeds present dormancy and often take several months to germinate. The tissue culture is a alternative form to propagate species. The objective was to establish and micropropagation $P$. foetida $L$., and create a germplasm bank. Seeds were scarified, disinfected, and inoculated on MS medium (1/2) without regulators for 66 days. Hypocotyls explants obtained of seedlings in vitro germinated were transferred and placed in the same medium supplemented with BAP $\left(1,0 \mathrm{mg} \mathrm{L}^{-1}\right)$. In the establishment phase of $45 \%$ of the explants sprouted and formed axillary buds. $88,9 \%$ of hypocotyl explants induced shoots and $11,1 \%$ produced callus. Seedling measuring $1,82 \mathrm{~cm}$ length and rooted were acclimatized.

Key words:Genebank, medicinal plants, micropropagation

\section{INTRODUÇÃO}

As Passifloraceae são predominantemente tropicais e subtropicais, com cerca de 20 gêneros e 650 espécies (Killip, 1938; Cervi, 1997; Ulmer \& MacDougal, 2004). Ocorrem nas áreas mais quentes da América com algumas espécies na Ásia e Austrália e uma espécie em Madagascar. No Brasil ocorrem quatro gêneros, Mitostemma Mast., Dilkea
Mast., Ancisthrothyrsus Harms e Passiflora L., com cerca de 120 espécies, a maioria subordinada ao gênero Passiflora (Killip, 1938).

A espécie Passiflora foetida L. pertence à seção Dysosmia, é possivelmente a que apresenta maior variedade no gênero, particularmente a respeito de folhas, flores e frutos (Ulmer \& MacDougal, 2004).

Recebido para publicação: setembro de 2011

Aceito para publicação: março de 2012

Rev. Bras. Pl. Med., Botucatu, v.14, n.esp., p.138-142, 2012. 
Apresenta ampla distribuição geográfica, ocorrendo na América tropical e frequentemente introduzida em outras regiões tropicais. É encontrada em Porto Rico, Jamaica e Antilhas além de ser amplamente distribuída por toda a América do Sul, inclusive Brasil (Bernacci, 2003).

$P$. foetida $L$. apresenta grande variabilidade anatômica, as ramas se estendem de 1,5 a $6 \mathrm{~m}$ de comprimento, o caule é cilíndrico, densamente piloso; as gavinhas surgem na axila foliar do lado sombreado do caule. As folhas são lobadas com brácteas e estípulas pedatissectas com segmento filiforme; frequentemente pilosas com tricomas glandulares capitadas nas folhas. $O$ florescimento se dá durante todo ano, onde a abertura das flores inicia-se pela manhã e o fechamento se dá antes do meio dia, juntamente com as brácteas e estipulas, possuem forte odor bem desagradável (Wagner et al., 1990). As sementes são achatadas, pretas em polpa doce e aromática (Swarbrick, 1981).

Os medicamentos fitoterápicos à base de maracujá devem ser elaborados a partir das espécies $P$. alata e $P$. incarnata, espécies oficiais da Farmacopéia Brasileira e Européia, respectivamente. Ao investigar o perfil de utilização de fitoterápicos pela população brasileira, alguns autores evidenciaram que Passiflora está entre os mais utilizados (Marliére et al., 2008; Silva et al., 2006; Ribeiro et al., 2005), e entre elas encontra-se a $P$. foetida $L$. sendo proposta pela etnobotânica a utilização de folhas e frutos no tratamento da asma, icterícia, bem como na forma de emplastros para as erisipelas e doenças de pele com inflamação (Chopra et al., 1944). Dentre os principais fitoconstituintes desta planta, encontramse alcalóides, fenóis, flavonóides e compostos glicosídicos cianogênicos (Dhawan et al., 2004), o que justifica a conservação, porém as sementes apresentam dormência e muitas vezes, levam alguns meses para germinar (Vanderplank, 2001).

Uma estratégia alternativa ao problema da germinação das sementes de $P$. foetida L., é a propagação in vitro, a qual permite regenerar plantas inteiras derivadas de sementes ou qualquer outra parte da planta. Mohamed et al. (1996) conseguiram germinar sementes de varias espécies de Passiflora in vitro, inclusive, de $P$. foetida $\mathrm{L}$.

Algumas espécies têm sido mantidas in vitro, mediante técnicas de cultura de tecidos. Há equipes integradas por profissionais especializados em desenvolver as técnicas necessárias ao estabelecimento de cada espécie, com aplicação imediata, redução de custo e necessidade mínima de espaço, o que tem feito com que essa técnica venha ganhando força e adeptos entre os mantenedores dos BAGs nacionais (Otoni et al., 1995).

Apesar de grande potencial morfogenético das espécies de Passiflora, até o momento, resultados concretos em termos de eficiência de protocolos de estabelecimento, desenvolvimento, regeneração e conservação in vitro não foram obtidos para a maioria das espécies. Alguns fatores têm contribuído para isso, dentre eles a variação da resposta entre genótipos, principalmente quando são utilizadas espécies selvagens, não cultivadas, que possuem grande variabilidade genética.

Uma vez que as diversas espécies de maracujazeiro respondem diferentemente a estímulos visando à indução da morfogênese, para o planejamento de experimentos que visem à conservação in vitro de germoplasma, o estabelecimento de um protocolo para a regeneração in vitro e a micropropagação de $P$. foetida $L$. é de grande importância na conservação e multiplicação desse importante germoplasma por apresentar ampla concentração de componentes químicos interessantes para a indústria farmacêutica e outras potencialidades, quase todas, ainda inexploradas, possibilitando a utilização em programas de melhoramento genético visando aumentar a produção dos princípios ativos dessa planta com grande potencial medicinal. Dentro deste contexto, o objetivo desse trabalho foi aprimorar o protocolo pré-estabelecido por Mohamed et al. (1996), usando como explante segmentos de hipocótilo derivados de sementes germinadas in vitro.

\section{MATERIAL E MÉTODO}

Foram coletados frutos maduros de Passiflora foetida L., acesso BGCCA-015, na casa de vegetação do Laboratório de Biotecnologia Vegetal do Centro de Ciências Agrárias da Universidade Federal da Paraíba (CCA/ UFPB). As sementes foram retiradas e submetidas ao processo de escarificação com lixa de madeira número 125. A desinfestação foi realizada com solução comercial de hipoclorito de sódio na proporção de 1:1(v/v) durante 20 minutos, seguido de três enxágües, com água destilada, deionizada e autoclavada. Todo o processo foi conduzido em câmara de fluxo laminar.

Após a desinfestação passando para o estabelecimento in vitro (experimento I) no qual, as sementes foram inoculadas em meio MS (Murashige \& Skoog, 1962) com metade da concentração de sais (MS $1 / 2$ ) e sem reguladores de crescimento. As culturas foram mantidas no escuro a $25 \pm 1^{\circ} \mathrm{C}$, durante duas semanas, posteriormente, foram submetidas ao fotoperíodo de $16 \mathrm{~h} / 8 \mathrm{~h}$ (luz/escuro) à temperatura de $25 \pm 1^{\circ} \mathrm{C}$ por 66 dias. Após esse período com auxílio de microscópio estereoscópico, as plântulas foram avaliadas quanto ao número de brotações, comprimento e diâmetro das plântulas, número de calos friáveis e número médio de gêmulas axilares.

Em experimento prévio, foram avaliadas

Rev. Bras. PI. Med., Botucatu, v.14, n.esp., p.138-142, 2012. 
diferentes concentrações de BAP $(0 ; 0,25 ; 0,5 ; 0,75$; e 1,0 $\left.\mathrm{mg} \mathrm{L}^{-1}\right)$. E a melhor resposta foi obtida com 1,0 $\mathrm{mg} \mathrm{L}^{-1}$. Seguindo este resultado prévio, para a micropropagação (experimento II), os explantes de hipocótilo foram transferidos para novo meio MS com todos os sais acrescido de $1,0 \mathrm{mg} \mathrm{L}^{-1}$ de BAP (6Benzilaminopurina), mantidos sob um fotoperíodo de $16 \mathrm{~h} / 8 \mathrm{~h}$ (luz/escuro) à temperatura de $25 \pm 1^{\circ} \mathrm{C}$, sendo subcultivadas a cada 30 dias. Após um período de 180 dias, foram avaliadas presença de raiz, formação de gemas axilares, calos friáveis, número de brotações e comprimento e diâmetro da plântula. Os dados foram transformados por $\sqrt{x+0,5}$ para estatística descritiva.

\section{RESULTADO E DISCUSSÃO}

Os coeficientes de variação $(C \vee \%)$ do experimento I variaram de 10,38 a $18,42 \%$ e para o experimento II de 4,16 a 61,53\%, segundo PimentelGomes \& Garcia (2002) valores de CV baixo são indicativos de precisão experimental (Tabelas 1 e 2).

$\mathrm{Na}$ fase de estabelecimento in vitro (experimento I) obteve-se $45 \%$ de brotações percentagem superior a obtida por Lombardi (2003), com $43,5 \%$ na formação de brotações e gemas axilares com o diferencial que o mesmo utilizou 0,5 $\mathrm{mg} \mathrm{L}^{-1}$ de BAP (6-Benzilaminopurina), já na formação de gemas axilares o presente trabalho obteve $45 \%$ com média de 0,76 brotos/explante e 0,77 gemas/ explante (Tabela 1; Figura 1), Falcão et al. (2009), em experimento também com $P$. foetida L., obtiveram entre 1,3 a 3,2 brotos/explante o qual o meio MS foi suplementado com BAP a $4,4 \mu \mathrm{M}$, sendo estas superiores as encontradas no presente trabalho, com o diferencial que nesta primeira fase não houve a adição de nenhum hormônio ao meio nutritivo. 50\% dos explantes apresentaram formação de calos, o que não é desejável quando de pretende conservar germoplasma ou propagação em larga-escala, pois a estabilidade genética pode não ser mantida, devido variações somaclonais (Faria et al., 2007). No experimento realizado por Zonta et al. (2005), para a germinação in vitro de sementes de Passiflora alata Dryand., foi necessário que as mesmas permanecessem embebidas em solução de GA3, o que proporcionou maior índice de velocidade na germinação, sendo um resultado interessante para quebra de dormência como na $P$. foetida L. uma vez que o estímulo pela giberelina, da síntese de enzimas como $\alpha$ e $\beta$ amilase que digerem as reservas armazenadas no endosperma, formando açúcares, aminoácidos e ácidos nucléicos, que são absorvidos e transportados para as regiões de crescimento do embrião, estimulando o alongamento celular, fazendo com que a raiz rompa o tegumento da

TABELA 1. Análise descritiva do estabelecimento in vitro de Passiflora foetida L. AREIA, UFPB, 2011.

\begin{tabular}{lccccc}
\hline Experimento I & $\begin{array}{c}\text { Número médio de } \\
\text { brotos/explante }\end{array}$ & $\begin{array}{c}\text { Comprimento médio } \\
\text { dasplântula }(\mathbf{c m})\end{array}$ & $\begin{array}{c}\text { Diâmetro médio da } \\
\text { plântula }(\mathbf{c m})\end{array}$ & $\begin{array}{c}\text { Número médio } \\
\text { decalos friáveis }\end{array}$ & $\begin{array}{c}\text { Número médio de } \\
\text { gêmulas axilares }\end{array}$ \\
\hline Médias & 0,76 & 0,76 & 0,56 & 0,17 & 0,77 \\
C.V. (\%) & 10,52 & 15,78 & 18,42 & 11,68 & 10,38 \\
\hline
\end{tabular}

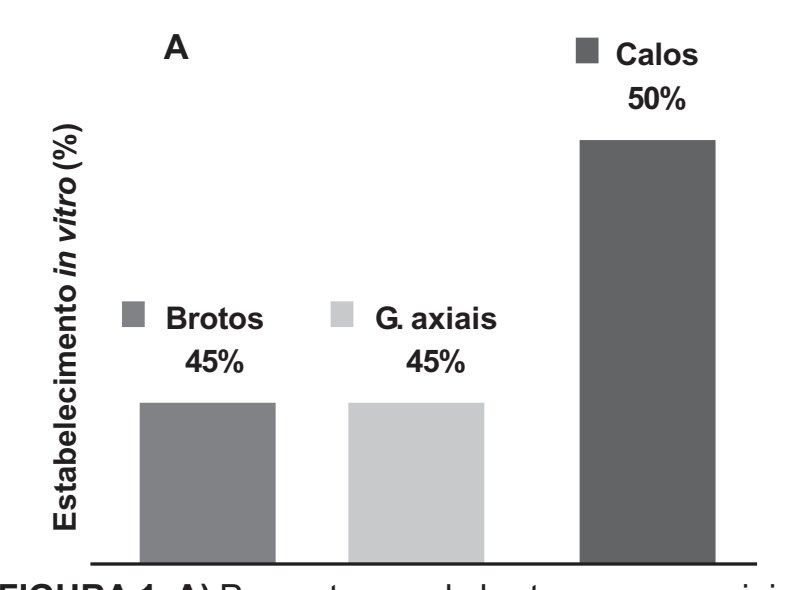

B

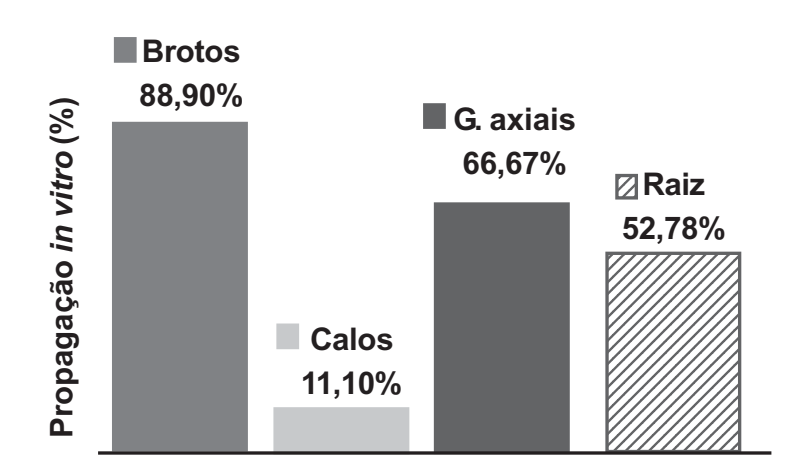

FIGURA 1. A) Porcentagem de brotos, gemas axiais e calos induzidos no estabelecimento in vitro de Passiflora foetida L. B) Porcentagem de brotos, gemas axiais, calos e raiz na propagação in vitro de Passiflora foetida $\mathrm{L}$. AREIA, UFPB, 2011. 
TABELA 2. Análise descritiva da micropropagação in vitro de Passiflora edulis L. AREIA, UFPB, 2011.

\begin{tabular}{lcccccc}
\hline $\begin{array}{c}\text { Experimento } \\
\text { II }\end{array}$ & $\begin{array}{c}\text { Comprimento } \\
\text { da raiz } \\
(\mathbf{c m})\end{array}$ & $\begin{array}{c}\text { Comprimento } \\
\text { médio da } \\
\text { plântula }(\mathbf{c m})\end{array}$ & $\begin{array}{c}\text { Diâmetro } \\
\text { médio da } \\
\text { plântula }\end{array}$ & $\begin{array}{c}\text { Número } \\
\text { médio de } \\
\text { calos friáveis }\end{array}$ & $\begin{array}{c}\text { Número médio } \\
\text { de gêmulas } \\
\text { axilares }\end{array}$ & $\begin{array}{c}\text { Número } \\
\text { médio de } \\
\text { brotos }\end{array}$ \\
\hline Médias & 0,97 & 1,82 & 1,55 & 0,99 & 1,44 & 1,69 \\
C.V. (\%) & 38,14 & 45,05 & 21,29 & 18,18 & 4,16 & 61,53 \\
\hline
\end{tabular}

semente, acelerando a germinação com maior uniformidade (Morley-Bunker, 1974).

$\mathrm{Na}$ fase de propagação (experimento II) $88,9 \%$ dos explantes de hipocótilo apresentaram brotações, estas foram superiores quando comparadas com Pinto et al. (2010) que obtiveram apenas $37 \%$ de brotações em segmentos de hipocótilo de Passiflora alata, onde o mesmo suplementou o meio MS com 1,0 $\mathrm{mg} \mathrm{L}^{-1}$ de BAP, $0,5 \mathrm{mg} \mathrm{L}^{-1}$ de TDZ e 4,0 $\mathrm{mg} \mathrm{L}^{-1}$ de AgNO3. Houve a formação de gemas axilares em $66,67 \%$ dos explantes com média de 1,44 gemas/explante (Tabela 2). As plântulas atingiram cerca de 1,82 $\mathrm{cm}$, resultados semelhantes foram obtidos por Faria et al. (2007), que cultivou em meio MS $1 / 2$ três espécies de Passiflora, conseguiram médias de $1,79 \mathrm{~cm}$ para $P$. edulis, $1,65 \mathrm{~cm}$ para $P$. giberti, e 1,36 cm para $P$. laurifólia.

$\mathrm{Na}$ Figura 1, pode-se observar a porcentagem de indução de calos, cerca de $11,1 \%$. Figueiredo et al. (2007) também notaram significativa formação de calos em explantes foliares de Passiflora gibertti e Passiflora edulis Sims., cultivados em meio MS suplementado com 4,4 mg $\mathrm{L}^{-1}$ de BAP e $5 \%$ de água de coco, em $P$. gibertti obteve-se em torno de $41,4 \%$ de formação de calos e em Passiflora edulis Sims., obteve-se média de $0,66 \%$, evidenciando a variabilidade existente em genótipos silvestres.

Obteve-se $52,78 \%$ de emissão de raízes nos explantes, com comprimento médio de 0,97 $\mathrm{cm}$, esta característica é importante para o desenvolvimento da planta principalmente na fase de aclimatação.

O meio MS é utilizado com sucesso na regeneração de microplantas para a maioria das espécies. Kantharajah \& Dodd (1990) e Kawata et al. (1995) obtiveram melhores respostas para desenvolvimento e multiplicação de gemas caulinares da espécie $P$. edulis Sims $\mathrm{f}$. edulis em meio MS suplementado com $0,23 \mathrm{mg} \mathrm{L}^{-1}$ de BAP e $0,20 \mathrm{mg} \mathrm{L}^{-1}$ de AIB.

Nas condições em que o trabalho foi executado, o protocolo para estabelecimento in vitro e micropropagação de Passiflora foetida L., mostrou-se eficiente e deve ser utilizado para a conservação e propagação vegetativa da espécie.

\section{REFERÊNCIA}

BERNACCI, L.C. Passifloraceae. In: WANDERLEY, M.L. et al. (Coords.). Flora fanerogâmica do Estado de São Paulo. São Paulo: FAPESP: RiMa, v.3, 2003. p.247-8. CERVI, A.C. Passifloraceae do Brasil: estudo do gênero Passiflora L., subgênero Passiflora. Madrid: Fontqueira XLV, 1997. 92p.

CHOPRA, R.N.; BADHWAR, R.L.; GHOSH, S. Poisonous plants of India. Public Service Commission, Govt. of West Bengal, Calcutta, India, 1944. 469p.

DHAWAN, K.; DHAWAN, S.; SHARMA, A. Passiflora: a review update. Journal of Ethnopharmacology, v.94, p.123, 2004.

FIGUEIREDO, M.A. et al. Indução in vitro de calos em duas espécies de maracujazeiro nativo. Revista Brasileira de Biociências, v.5, p.288-90, 2007.

FARIA, G.A. et al. Meio de cultura e tipo de explante no estabelecimento in vitro de espécies de maracujazeiro. v.66, 2007. 535p.

FALCÃO, E.; GARCIA, R.O.; MANSUR PACHECO, G. Regeneração in vitro de Passiflora foetida $\mathrm{L}$. a partir de explantes caulinares. In: SEMANA DE INICIAÇÃO CIENTÍFICA/UERJ, 19., 2009, Rio de Janeiro. Anais... Rio de Janeiro: UERJ, 2009. p.43.

KAWATA, K. et al. Micropropagation of passion fruit from subcultured multiple shoot primordia. Journal of Plant Physiology, v.147, p.281-4, 1995.

KANTHARAJAH, A.S.; DODD, W.A. In vitro micropropagation of passiflower edulis (purple passionfruit). Annals of Botany, v.65, p.337- 9, 1990.

KILLIP, E.P. The American species of Passifloraceae. Field Museum of Natural History, Botanical Séries, v.19, p.1-613, 1938.

MARLIÉRE, L.D.P. et al. Utilização de fitoterápicos por idosos: resultados de um inquérito domiciliar em Belo Horizonte (MG), Brasil. Revista Brasileira Farmacognosia, v.18, p.754-60, 2008.

MOHAMED, M.E.; HICKS, R.G.T.; BLAKESLEY, D. Shoot regeneration from mature endosperm of Passiflora foetida. Plant Cell Tissue and Organ Culture, v.46, p.1614, 1996.

MORLEY-BUNKER, M.J.S. Some aspects of seed dormancy with reference to Passiflora spp. and other tropical and subtropical crops. Londres: University of London, 1974. 43p.

MURASHIGE, T.; SKOOG, F. A revised medium for rapid growth and bioassays with tobacco tissue cultures. Physiologia Plantarum, v.15, p.473-9, 1962.

OTONI, W.C. et al. Somatic hybridization of the Passiflora species, $P$. edulis f. flavicarpa Degener and $P$. incarnata $\mathrm{L}$. Journal of Experimental Botany, v.46, n.288, p.777-85, 1995. 
PIMENTEL-GOMES, F.; GARCIA, C.H. Estatística aplicada a experimentos agronômicos e florestais: exposição com exemplos e orientações pra uso de aplicativos. Piracicaba: FEALQ, 2002. 309p.

PINTO, A.P.C. et al. In vitro organogenesis of Passiflora alata. In vitro Cell Development. São Paulo: ESALQ/USP, 2010. p.28-33.

RIBEIRO, A.Q.; LEITE, J.P.V.; DANTAS-BARROS, A.M. Perfil de utilização de fitoterápicos em farmácias comunitárias de Belo Horizonte sob a influência da legislação nacional. Revista Brasleira Farmacognosia, v.15, p.65-70, 2005.

SILVA, M.I.G. et al. Utilização de fitoterápicos nas unidades básicas de atenção à saúde da família no município de Maracanaú (CE). Revista Brasileira
Farmacognosia, v.16, p.455-62, 2006.

ULMER, T.; MACDOUGAL, J.M. Passiflora: Passionflowers of the world. Portland: Timber Press. 2004. p.27.

VANDERPLANK, J. Passion flowers. Cambridge: The MIT Press. 2001. 225p.

WAGNER, W.L.; HERBST, D.R.; SOHMER, S.H. Manual of the flowering plants of Hawai'i. 2 vol. Honolulu: University of Hawaii Press \& Bishop Museum Press, 1990. 853p.

ZONTA, J.B. et al. Germinação de sementes do maracujazeiro (Passiflora alata Dryand) submetidas a tratamentos físicos no tegumento e a préembebição em ácido giberélico (GA3). Encontro latino americano de pós- graduação, 5., 2005. Anais... Universidade Vale do Paraíba. 2005. 